\title{
Predictive Virtual Patient Modelling of Mechanical Ventilation: Impact of Recruitment Function
}

\author{
Sophie E. Morton (i), ${ }^{1}$ Jennifer L. Knopp,${ }^{1}$ J. Geoffrey Chase, ${ }^{1}$ Knut Möller, ${ }^{2}$ Paul Docherty, ${ }^{1}$ \\ Geoffrey M. Shaw, ${ }^{3}$ and Merryn Tawhai ${ }^{4}$ \\ ${ }^{1}$ Department of Mechanical Engineering, University of Canterbury, Christchurch, New Zealand; ${ }^{2}$ Institute of Technical \\ Medicine, Furtwangen University, Villingen-Schwenningen, Germany; ${ }^{3}$ Department of Intensive Care, Christchurch Hospital, \\ Christchurch, New Zealand; and ${ }^{4}$ Auckland Bioengineering Institute, The University of Auckland, Auckland, New Zealand
}

(Received 21 December 2018; accepted 22 March 2019; published online 29 March 2019)

Associate Editor Dan Elson oversaw the review of this article.

\begin{abstract}
Mechanical ventilation is a life-support therapy for intensive care patients suffering from respiratory failure. To reduce the current rate of ventilator-induced lung injury requires ventilator settings that are patient-, time-, and disease-specific. A common lung protective strategy is to optimise the level of positive end-expiratory pressure (PEEP) through a recruitment manoeuvre to prevent alveolar collapse at the end of expiration and to improve gas exchange through recruitment of additional alveoli. However, this process can subject parts of the lung to excessively high pressures or volumes. This research significantly extends and more robustly validates a previously developed pulmonary mechanics model to predict lung mechanics throughout recruitment manoeuvres. In particular, the process of recruitment is more thoroughly investigated and the impact of the inclusion of expiratory data when estimating peak inspiratory pressure is assessed. Data from the McREM trial and CURE pilot trial were used to test model predictive capability and assumptions. For PEEP changes of up to and including $14 \mathrm{cmH}_{2} \mathrm{O}$, the parabolic model was shown to improve peak inspiratory pressure prediction resulting in less than $10 \%$ absolute error in the CURE cohort and $16 \%$ in the McREM cohort. The parabolic model also better captured expiratory mechanics than the exponential model for both cohorts.
\end{abstract}

Keywords-In-silico, Intensive care, Mechanical ventilation, PEEP, Prediction, Virtual patient.

Address correspondence to Sophie E. Morton, Department of Mechanical Engineering, University of Canterbury, Christchurch, New Zealand. Electronic mails: sophie.morton@pg.canter bury.ac.nz, jennifer.knopp@canterbury.ac.nz, geoff.chase@canter bury.ac.nz, moe@hs-furtwangen.de, paul.docherty@canterbury. ac.nz, geoff.shaw@cdhb.health.nz,m.tawhai@auckland.ac.nz

\section{INTRODUCTION}

Mechanical ventilation (MV) is a core therapy for intensive care unit (ICU) patients who are suffering from respiratory failure. ${ }^{41}$ However, ventilator settings that are optimal for one patient may cause ventilator induced lung injury (VILI) ${ }^{2,9,27,42,55}$ in another patient who has different respiratory mechanics or dysfunction. Thus, inter-patient and intra-cohort heterogeneity in response to MV makes selecting ventilator settings that can optimise oxygenation and gas exchange-while minimising the potential for VILI - difficult in practice. ${ }^{23}$

A range of lung protective strategies has been developed to optimise ventilation, including the use of low tidal volumes and moderating driving pressure. ${ }^{3,9}$ In general, most strategies set positive end-expiratory pressure (PEEP) at or above a threshold where injured alveoli do not collapse at the end of expiration, because repetitive opening and closing can cause considerable damage. ${ }^{10}$ Research has also indicated that PEEP should be set to the pressure that corresponds to the minimum respiratory elastance in response to the pressure or volume delivered. ${ }^{3,44,47}$ Finally, staircase recruitment manoeuvres (RM) incrementally increase PEEP with the goal of recruiting obstructed or collapsed alveoli at a given pressure. ${ }^{6}$ Each approach attempts to find a 'best' setting.

In particular, RMs can be highly effective, resulting in additional end-expiratory lung volume that contributes to gas exchange function, or recruitment of dynamic functional residual capacity $\left(V_{\mathrm{frc}}\right)$ at a given PEEP due to an increase in open alveoli. ${ }^{18,56,59}$ However, both healthy and injured alveoli are subjected to the same pressures and volumes. Hence, RMs also 
subject the patient to risk due to the higher pressures or volumes induced. ${ }^{7}$ Therefore ventilator settings and RM design need to be patient specific and vary with condition, ${ }^{17}$ however current protocols cannot offer this level of personalisation.

A range of pulmonary elastance models have been developed to describe lung mechanics throughout ventilation. These have ranged from finite element models that provide detailed physiological information ${ }^{14,32,48,50-53}$ to lumped parameter models ${ }^{16,45,49}$ that can be used at the bedside to advise clinical decisions. However, these models all lack the capability of predicting the effect of a change in treatment prior to implementation.

A predictive pulmonary elastance model ${ }^{31}$ was developed to predict the impact of PEEP changes on lung mechanics throughout a staircase RM. ${ }^{35}$ This model uses physiologically relevant 'basis function' models for elastance and resistance changes over PEEP steps to estimate $V_{\text {frc }}$ and predict peak inspiratory pressure (PIP) over PEEP steps in RMs. The ability to predict lung response prior to changing ventilator settings would allow clinicians to better assess the trade-off between risk (high pressures and PIP) and reward (alveolar recruitment (increased $V_{\text {frc }}$ ) and improved gas exchange).

This work compares the exponential recruitment model of Ref. 35 against a parabolic recruitment model to determine how to best predict PIP during RMs. Prior research indicates that recruitment rate with increasing pressure follows an exponential decay. ${ }^{1,5,15,24,25,33,34,37-39,46,58,60}$ This new model challenges the assumption that recruitment models must also be exponential since recruitment over pressure is a complex mechanical behaviour that is not driven solely by pressure and volume. Sensitivity analyses of the new model assesses the robustness of model parameter choices and assumptions. This new model also differs in its use of inspiration and expiration data, rather than just using inspiration data (as in Ref. 35). The addition of expiration data improves the ability of the model to capture derecruitment that occurs during expiration.

Finally, model comparison and validation is performed over two added patient cohorts with significantly more data than in Ref. 35 to evaluate more robust conclusions.

\section{METHODS}

\section{Patient Data}

Pressure and flow data from $\mathrm{N}=21$ invasively ventilated patients diagnosed with Acute Respiratory Distress Syndrome (ARDS) from intensive care units (ICUs) in Germany $(\mathrm{N}=17)$ and New Zealand
$(\mathrm{N}=4)^{16,43}$ is analysed. The four patients from New Zealand were part of the CURE pilot trial conducted at Christchurch Hospital ICU in August 2016. Pressure-flow data for this cohort was sampled at $50 \mathrm{~Hz}^{49}$ The German data spans eight ICUs, and was collected from September 2000 until February 2002 as part of the McREM trial. ${ }^{43}$ It was sampled at $125 \mathrm{~Hz}$. All patients were fully sedated and received invasive volume-controlled ventilation via an endotracheal tube (ETT).

\section{CURE Data}

Pilot trial patients were treated as part of the CURE trial [(ANZTR Number: ACTRN126130 010 06730)]. ${ }^{16}$ The New Zealand Southern Regional Ethics Committee granted ethics approval for this pilot trial. Inclusion criteria included invasively ventilated patients with $\left(\mathrm{PaO}_{2} / \mathrm{FiO}_{2}\right) \mathrm{PF}<300 \mathrm{mmHg}$ (maximum studied: $\mathrm{PF}=209 \mathrm{mmHg}$ ) and patients were excluded if their APACHE III diagnostic codes were associated with prior pulmonary disease admission (asthma, COPD), neurological diseases or injuries, spinal injury, or head trauma. Patients were ventilated with a Puritan Bennett 840 ventilator (Covidien, Boulder, CO, USA). Demographics are shown in Table 1. Tidal volume was set to $6-8 \mathrm{ml} / \mathrm{kg}$ of initial body weight. Respiratory rate was increased to 30 breaths per minute if there was no significant autoPEEP detected.

Each patient underwent a staircase RM with two incremental and two decremental changes in PEEP in a manner shown in Fig. 1a. By design, PEEP was set to be increased in increments of $4 \mathrm{cmH}_{2} \mathrm{O}$, giving a maximum PEEP change of $12 \mathrm{cmH}_{2} \mathrm{O}$ over the entire manoeuvre. However, sometimes PEEP targets were not met internally by the ventilator. This failure does not affect this analysis, where the current PEEP is taken as the nearest whole number of the pressure at the onset of inspiration. Resultant PEEP changes of less than $2 \mathrm{cmH}_{2} \mathrm{O}$ were ignored $(\mathrm{N}=6)$. Only the two increasing arms of the recruitment manoeuvres were studied, providing manoeuvres for the four patients. PEEP levels including less than eight breaths $(\mathrm{N}=34)$ were excluded as the settling time at a new PEEP level can exceed this number of breaths or dominates the breath sample. ${ }^{57}$ Figure 1a shows a typical RM carried out in this study.

\section{McREM Data}

The McREM trial examined whether or not lung mechanical observations differed between measurements taken under static conditions and those taken dynamically. The study had ethics approval under the local ethics committee of each of the eight German 
TABLE 1. Patient demographics for CURE trial data $(N=4)$.

\begin{tabular}{lccclc}
\hline Patient \# & Sex & Age (years) & LoMV (days) & Clinical diagnostic & P/F ratio \\
\hline 1 & M & 33 & 23 & Peritonitis & 177 \\
2 & M & 77 & 24 & Legionella pneumonia & 209 \\
3 & M & 61 & 23 & Staphylococcus Aureus pneumonia & 109 \\
4 & F & 73 & 2 & Streptococcus pneumonia & 155 \\
\hline
\end{tabular}
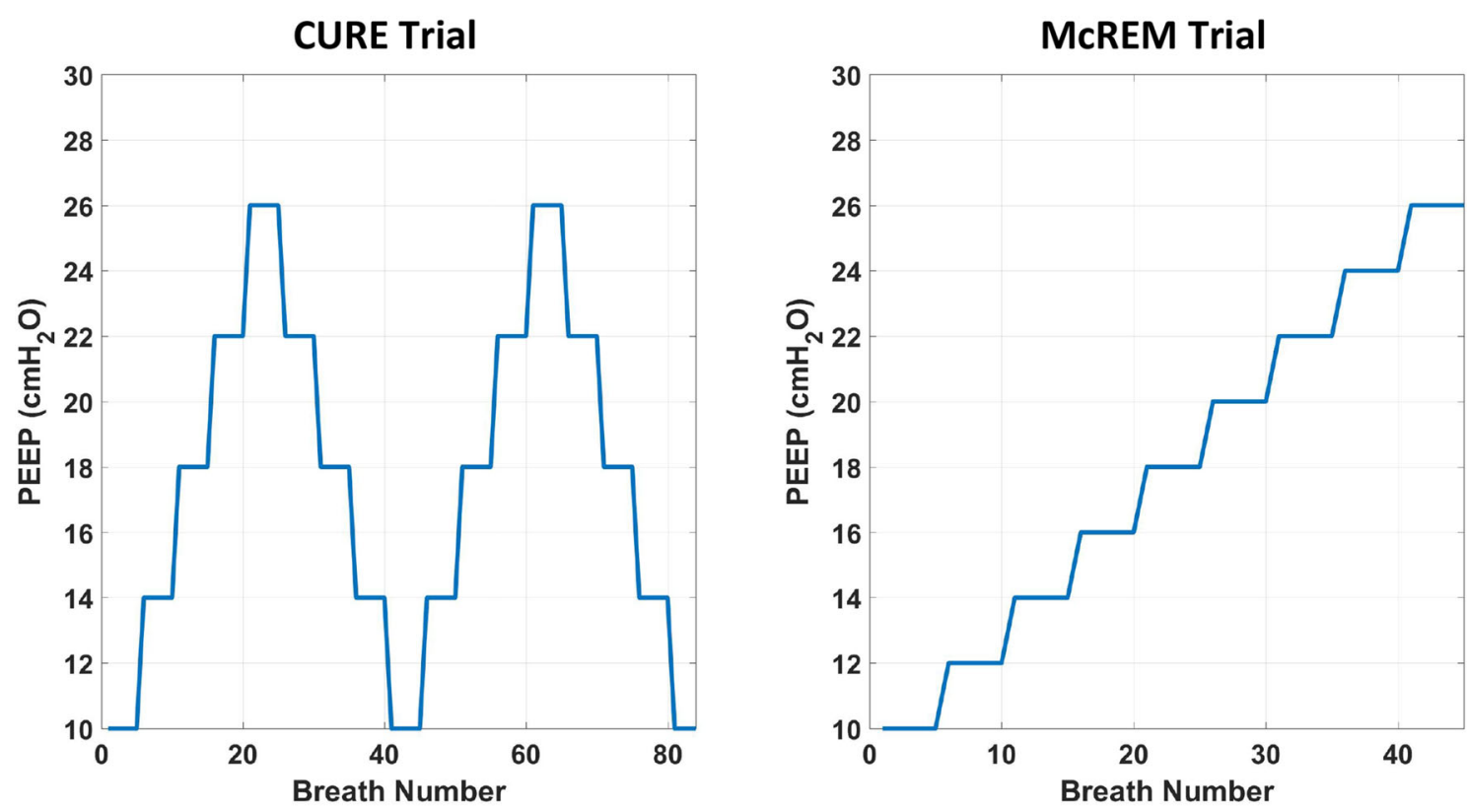

FIGURE 1. Example of RMs used in CURE and McREM trials. The number of breaths spent at each PEEP level are not representative of those found in the data.

ICUs participating in the trial. ${ }^{43}$ All patients were ventilated with a Draeger Evita 4 (Draeger Medical, Lübeck, Germany) ventilator. Exclusion criteria included patients with obstructive lung disease, presence of a bronchopleural fistula or known air leakage, haemodynamic instability, or being considered ready to wean off ventilation by the attending physician. The maximum $\quad \mathrm{PF}=298 \mathrm{mmHg} \quad(\mathrm{PF}<300 \mathrm{mmHg})$, which matches the inclusion criteria for CURE. The tidal volume was targeted at $8 \pm 2 \mathrm{~mL} / \mathrm{kg}$ initial body weight. Before the measurements, respiratory rate was adjusted to keep the $\mathrm{PaCO}_{2}$ at around $55 \mathrm{mmHg}$. Inspiratory time and flow rate were set to obtain an end-inspiratory hold of $0.2 \mathrm{~s}^{43}$ During the protocol, ventilator settings remained unchanged. Patient demographics are shown in Table 2.

Each patient underwent a staircase recruitment manoeuvre where PEEP was increased in steps of 2 $\mathrm{cmH}_{2} \mathrm{O}$ up to 13 times from ZEEP or to a limit of 26 $\mathrm{cmH}_{2} \mathrm{O}$. The McREM study included 28 patients, of which only 17 received RMs that could be used in this study. These latter patients were used in this analysis.
Each PEEP step was maintained for 10 breaths. $^{43}$ Figure 1 shows a typical RM carried out in this study.

\section{Model Definition}

The model used in this study is significantly extended from a previously developed predictive pulmonary elastance model. ${ }^{35}$ It was initially developed from a well-validated single-compartment model. ${ }^{4,13}$

$$
P(t)=E V(t)+R Q(t)+\mathrm{PEEP}
$$

where $P(t)$ is the airway pressure delivered by the ventilator $\left(\mathrm{cmH}_{2} \mathrm{O}\right)$, PEEP is the positive end-expiratory pressure $\left(\mathrm{cmH}_{2} \mathrm{O}\right), Q(t)$ is the flow of air delivered by the ventilator $(\mathrm{L} / \mathrm{s})$, and $V(t)$ is the volume of air delivered to the lungs (L). $V(t)$ is the integral of $Q(t)$, starting at $t=0$ for each breath. Pulmonary elastance $\left(\mathrm{cmH}_{2} \mathrm{O} / \mathrm{L}\right)$ and pulmonary resistance $\left(\mathrm{cmH}_{2} \mathrm{O} * \mathrm{~s} / \mathrm{L}\right)$ are defined by $E$ and $R$, respectively, and identified from measured data. ${ }^{12}$

The general elastance and resistance basis function shapes used in the new model are shown in Fig. 2 and 
TABLE 2. Patient demographics for McREM trial. ${ }^{43}$

\begin{tabular}{|c|c|c|c|c|c|}
\hline Patient \# & Sex & Age & LoMV (days) & Clinical diagnostic & $\mathrm{P} / \mathrm{F}$ ratio \\
\hline 1 & M & 37 & 10 & Pneumonia & 163 \\
\hline 2 & M & 39 & 2 & Traumatic aortic dissection, lung contusion & 170 \\
\hline 3 & $\mathrm{~F}$ & 50 & 8 & Pancreatitis, pneumonia & 202 \\
\hline 4 & $\mathrm{~F}$ & 49 & 3 & Pneumonia & 289 \\
\hline 5 & M & 34 & 10 & Traumatic open brain injury & 192 \\
\hline 6 & M & 67 & 4 & Post-resuscitation & 234 \\
\hline 7 & M & 39 & 10 & Perf. sigma, peritonitis & 188 \\
\hline 8 & M & 42 & 9 & Pneumonia, pancreatitis & 235 \\
\hline 9 & M & 51 & 5 & Traumatic brain injury, pneumonia & 230 \\
\hline 10 & $\mathrm{M}$ & 77 & 6 & Pneumonia & 225 \\
\hline 11 & M & 74 & 10 & Subarachnoid and subdural haemorrhage & 298 \\
\hline 12 & M & 41 & 16 & Peritonitis & 178 \\
\hline 13 & M & 62 & 2 & Subarachnoid haemorrhage & 288 \\
\hline 14 & M & 39 & 7 & Traumatic brain injury, pneumonia & 143 \\
\hline 15 & M & 74 & 9 & S/P coronary artery, bypass grafting, pneumonia & 271 \\
\hline 16 & M & 59 & 19 & ARDS & 75 \\
\hline 17 & M & 45 & 8 & Blunt abdominal trauma, pneumonia & 173 \\
\hline
\end{tabular}

\section{Basis Function for Elastance (Recruitment)}

$$
\Phi_{1}=\left(V-V_{m}\right)^{2}
$$

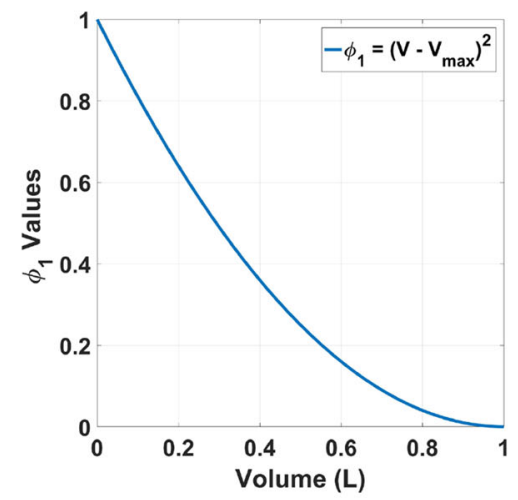

\section{Basis Function for Elastance (Distension)}

$$
\Phi_{2}=\frac{P(t)}{60}
$$

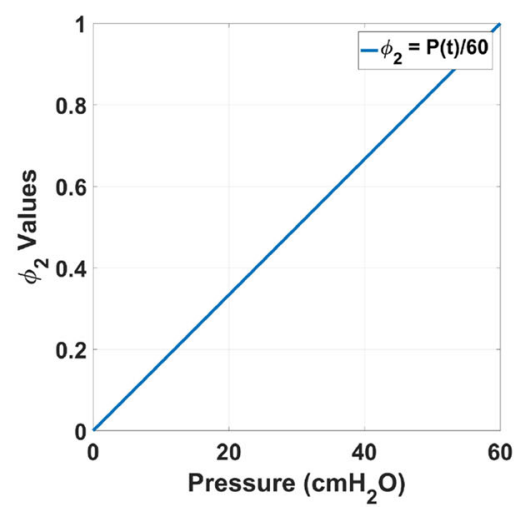

\section{Basis Functions for Resistance}

$$
\vartheta_{1}=1, \vartheta_{2}=|Q(t)|
$$

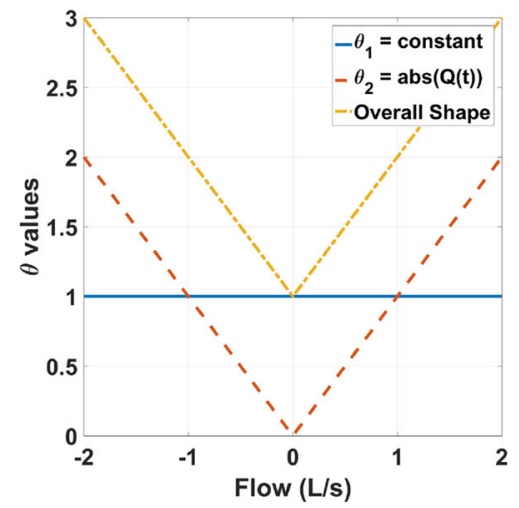

FIGURE 2. Depiction of basis functions for elastance and resistance. The shapes above assume coefficient values of 1 . All basis functions are dimensionless.

are defined over the pressure range $0-60 \mathrm{cmH}_{2} \mathrm{O}$ and volume range $0-1 \mathrm{~L}$ for the elastance basis functions, and a flow range -2 to $2 \mathrm{~L} / \mathrm{s}$ for the resistance basis functions. These ranges more than cover typical mechanical ventilation ranges.

Pulmonary elastance is defined as a function of both volume and pressure, in two separate basis functions, shown in Fig. 2. This split allows more specific physiological behaviours of the lungs to be captured, compared with the single, lumped parameter in Eq. (1).

The recruitment elastance, captures the decreasing rate of recruitment of alveoli with an increase in vol- ume delivered. This recruitment function is piecewise parabolic with respect to lung volume above lung volume at ZEEP (ventilator set zero end-expiratory pressure) and defined as zero when $V>V_{\mathrm{m}}$. $V_{\mathrm{m}}=1 \mathrm{~L}$ throughout the study as this represents a sensible upper limit on gained recruited volume at the PEEP changes studied, based on clinical observation. As this parameter cannot be easily uniquely identified for each individual patient, its value is set constant. In contrast, Morton et al. ${ }^{35}$ used an exponential function rather than a parabolic, which can be seen in Eq. (3). Henceforth, this original model shown in Ref. 35 will 
be referred to as the 'exponential model' while the adapted parabolic model will be called the "parabolic model'.

The distension function captures the increasing elastance with pressure due to distension effects and is modelled as a linear function: where the value of 60 is the maximum MV pressure considered. This is well above peak limits that are observed or considered safe, ${ }^{8}$ and is the same as in Ref. 35 .

Resistance is a function of flow. Resistance was also defined as in Ref. 35 by the Rohrer equation for flow resistance. ${ }^{21,40}$ These terms capture linear and nonlinear components of flow resistance, and $R_{1}$ and $R_{2}$ are constants to be identified. This equation is also similar to those used to model endotracheal tube resistance $^{21,28}$ which is a major form of resistance encountered in MV.

Combining both the elastance and resistance basis functions into the model of Eq. (1) yields Eq. (2) for the parabolic model. The original, exponential recruitment model can be seen in Eq. (3).

$$
\begin{aligned}
P(t)= & (\underbrace{E_{1}\left(V-V_{m}\right)^{2}}_{\text {recruitment elastance }}+\underbrace{E_{2} \frac{P(t)}{60}}_{\text {distension elastance }}) V(t) \\
& +(\underbrace{R_{1}+R_{2}|Q(t)|}_{\text {Rohrer resistance }})+Q(t)+\text { PEEP, } \\
P(t)= & (\underbrace{E_{1} e^{-b V(t)}}_{\text {recruitment elastance }}+\underbrace{E_{2} \frac{P(t)}{60}}_{\text {distension elastance }}) V(t) \\
& +(\underbrace{R_{1}+R_{2}|Q(t)|}_{\text {Rohrer resistance }}) Q(t)+\text { PEEP },
\end{aligned}
$$

where $E_{1}, E_{2}, R_{1}$, and $R_{2}$ are to be identified and the other variables are known.

Figure 2 shows each basis function component. Note that as pressure rises with volume during inspiration, the two basis functions create an overall parabolic shape in combination. This cannot be directly plotted as they are functions of pressure and volume whose relationship differ for each patient and with MV settings. However, Fig. 3 shows the contrast between this model and the model used in Ref. 35 in terms of the parabolic vs. exponential recruitment basis functions.

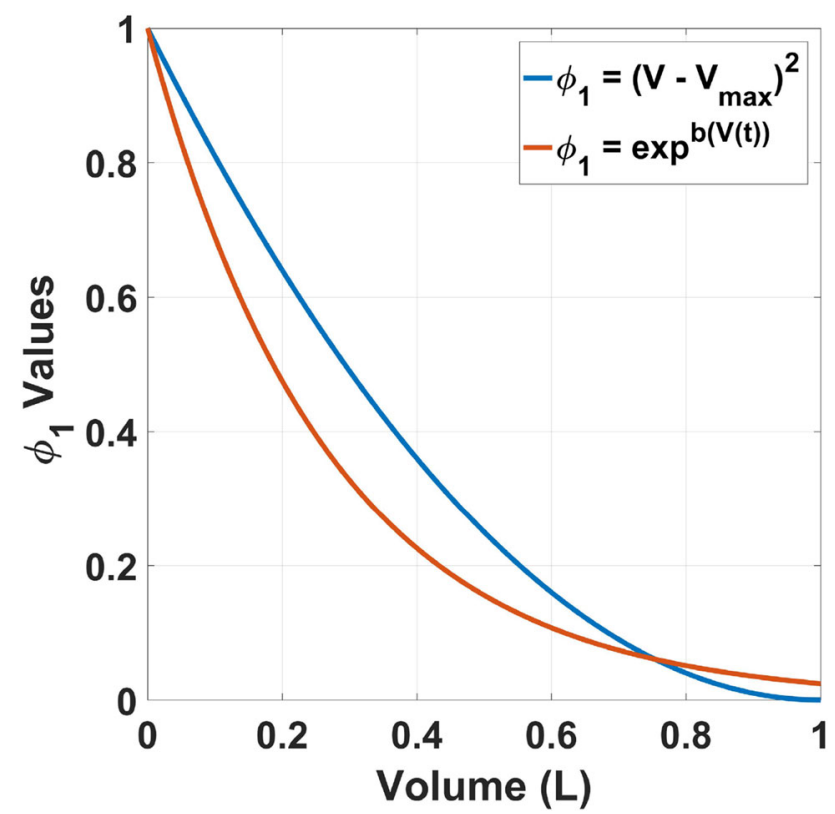

FIGURE 3. Difference in shape between the exponential recruitment function used in Ref. 37 and the new parabolic recruitment function.

\section{Model Identification}

\section{Identification and Fitting}

Data from the entire breath was used to identify model parameters to identify $E_{1}, E_{2}, R_{1}$, and $R_{2}$ using Eq. (2), rather than just inspiration data as in Ref. 35. In an additional change from the work in Ref. 35, the first data points of each breath were used in identification to capture the viscoelastic behaviour present in this section of ventilation.

An identified model can be subsequently used to predict outcomes for different settings or pressure and volume, as the basis functions are identified over an entire reasonable range of these variables. A median breath was taken from all but the first breath at a PEEP level. Model parameters, $E_{1}, E_{2}, R_{1}, R_{2}$ were then identified for this median breath using the linear least squares lsqnonneg function to constrain all parameters to physiologically possible positive values in MATLAB and clinical data in a problem defined as

$$
\begin{aligned}
& {\left[\begin{array}{cccc}
\min \left(0, V\left(t_{i}\right)-V_{m}\right)^{2} \odot V\left(t_{i}\right) & V\left(t_{i}\right) \odot \frac{P\left(t_{i}\right)}{60} & Q\left(t_{i}\right) & \left|Q\left(t_{i}\right)\right| Q\left(t_{i}\right) \\
\vdots & \vdots & \vdots & \vdots
\end{array}\right]} \\
& {\left[\begin{array}{c}
E_{1} \\
E_{2} \\
R_{1} \\
R_{2}
\end{array}\right]=\left[\begin{array}{c}
P\left(t_{i}\right)-\text { PEEP } \\
\vdots
\end{array}\right],}
\end{aligned}
$$

where $\odot$ indicates pointwise multiplication. 
This parameter fit was done independently for every PEEP level in a patient data set. Once a PEEP level was fit, forward prediction to other PEEP levels was achieved using the parameters from the current PEEP level only

\section{Prediction}

Forward simulation of $P(t)$ using $V(t)$ and $Q(t)$ given by the volume controlled ventilation mode at different PEEP levels as inputs can be used to assess prediction, and thus the potential clinical utility of the model and overall approach. Prediction across PEEP levels requires calculation of the change in $V_{\mathrm{frc}}$ or the volume recruited by a PEEP step change relative to the current PEEP. ${ }^{30,56} \mathrm{It}$ is assumed that the change in $V_{\mathrm{frc}}$ is positive or zero when PEEP is increased, and negative or zero when PEEP is decreased.

Equation (5) was used to determine the change in $V_{\text {frc }}$ across a particular PEEP step $(n$ to $n+1)$. The minimum value for $\mathrm{V}-\mathrm{V}_{\mathrm{m}}$ was set to zero through use of the min function in Matlab. ${ }^{54}$

$$
V_{\mathrm{frc}}^{n}=\frac{\left(\mathrm{PEEP}_{n+1}-\mathrm{PEEP}_{n}\right)}{E_{1}\left(V-V_{m}\right)^{2}+E_{2} \mathrm{PEEP}_{n+1} / 60} .
$$

Incorporating $V_{\text {frc }}^{n}$ from Eq. (5) yields a model to predict $P(t)$ using Eq. (2) and the known volume controlled flow inputs at a new PEEP level $\left(\right.$ PEEP $\left._{n+1}\right)$, where the resulting equation is

$$
\begin{aligned}
P(t)= & \left(E_{1}\left(\left(V+V_{\mathrm{frc}}\right)-V_{m}\right)^{2}+E_{2} \frac{P(t)}{60}\right) V(t) \\
& +\left(R_{1}+R_{2}|Q(t)|\right) Q(t)+\operatorname{PEEP}_{n+1} .
\end{aligned}
$$

\section{Model Validation}

\section{Error Analysis}

The same error metrics are used to describe the identified model fit to data, and the accuracy of the identified model prediction for a higher PEEP level. Root mean square (RMS) indicates the average sumsquared error residuals throughout the breath. To ensure that this value is normalised across all PEEP levels and between data sets with different numbers of data points per breaths, the percentage RMS error is also calculated.

PIP is a key clinical indicator of the risk of VILI due to barotrauma in volume controlled ventilation. ${ }^{20,22}$ To assess the clinical relevance and safety of the model, both the absolute error in PIP and its percentage error are calculated for identified model fit and prediction. Finally, predictions are made for 1-8 PEEP steps for- ward for all PEEP levels where there was data. To assess the accuracy of the model across the entire PEEP range, model fit and prediction error are compared across the entire range and for different prediction step sizes.

\section{Model Error Sensitivity Analyses}

Several analyses were done to quantify the impact of the difference in recruitment elastance basis function shape $\left(\Phi_{1}\right)$ and the impact of modelling decisions on the accuracy of model identification and PIP prediction. Specifically:

\section{Impact of Basis Function Shape}

The parabolic recruitment function of Eq. (2) is compared to a previous model ${ }^{35}$ shown in Eq. (3). Equations (2) and (3), while broadly describing elastance as decreasing to a minimum of zero, differ in the shape of that decrease, as shown in Fig. 3 where the exponential of Eq. (3) has a much steeper initial drop from its maximum value. This comparison can indicate which definition is better across all the data in this study, noting that an exponential shape has been very commonly used in previous studies. ${ }^{15,34,37,46,58}$

\section{Impact of the Inclusion of Expiratory Data in Model Fit and Prediction}

The model was identified and used for prediction for three cases to test the minimum amount of data required for prediction, and whether the expiratory section of the breath contains different dynamics. Expiration is defined as the point at which ventilator flow first becomes negative after PIP is reached. In the McREM protocol this point is reached after an endinspiratory pause. The first breath at each PEEP level was discounted, as often this breath contains unusual dynamics that are not seen in later breaths due to ventilator PEEP regulation and the time dependence of alveolar recruitment. ${ }^{5,26}$ In addition, the first five data points of each breath were excluded, as these points are more reflective of ventilator PUMP [PEEP adjustment and Monitoring Procedure (PUMP)] dynamics than the pressure response of the lung.

The following cases are analysed and compared:

1. The full breath

2. Only the inspiratory section of the breath.

3. Only the inspiratory section with prediction across the entire breath.

The first two cases both identify the model and predict over the specified portions of the breathing cycle. The last case assesses whether expiration con- 
tains unique dynamics, and thus identifies the model over only a portion of the breath, while assessing its performance across the entire breath. Unless otherwise stated (as in "Inclusion of Expiratory Data", Fig. 9 and Table 5), all results in this paper fit and predict across both inspiration and expiration.

\section{RESULTS}

\section{Model Fit}

Using the parabolic model as presented, the identified model fit errors were low for both the CURE and the McREM cohorts as shown in Table 3.

The $\mathrm{R}_{2}$ value was $0 \mathrm{cmH}_{2} \mathrm{O} * \mathrm{~s} / \mathrm{L}$ in most cases as it is constrained from being non-physically negative. The Rohrer equation's second term using $(|Q| Q)$ is for high energy flows, where the laminar flows and geometry in mechanical ventilation often do not reach these levels. However, in some cases it is needed for a more accurate fit.

\section{Model Prediction}

The fitted elastance curves for each PEEP level are shown for two cases in Fig. 4. When curve was offset with the estimated $\Delta V_{\text {frc }}$ change from the starting PEEP level, they overlapped into a parabolic shape in most cases studied. As expected, the recruitment elastance was often steeper earlier in the recruitment manoeuvre than at higher PEEP levels such as 20 or 22 $\mathrm{cmH}_{2} \mathrm{O}$ where distension is expected to be the primary dynamic.

Model predictions for the parabolic model have low RMS and PIP prediction errors across all PEEP changes studied, as shown in Table 4 . While there is some increase in error with increases in the PEEP prediction intervals of $2-12 \mathrm{cmH}_{2} \mathrm{O}$ (1-6 PEEP steps) these errors are similar to the fitting errors in Table 3. The cumulative distribution functions (CDFs) in Fig. 5

TABLE 3. Summarised fitting error (median [IQR]), along with averaged cohort parameters $\left(1 \mathrm{cmH}_{2} \mathrm{O}=98.07 \mathrm{~Pa}\right)$.

\begin{tabular}{lll}
\hline & \multicolumn{1}{c}{ CURE cohort } & McREM cohort \\
\hline $\mathrm{E}_{1}$-recruitment & $4.8[0.7-12.9]$ & $14.0[10.1-19.2]$ \\
$\mathrm{E}_{2}$-distension & $55.2[48.4-70.6]$ & $47.0[41.1-58.6]$ \\
$\mathrm{R}_{1}$ & $6.5[5.9-7.0]$ & $8.5[7.5-11.0]$ \\
$\mathrm{R}_{2}$ & $0.0[0.0-0.0]$ & $0.0[0.0-0.0]$ \\
$\#$ of PEEP levels studied & 49 & 89 \\
RMS error $\left(\mathrm{cmH}_{2} \mathrm{O}\right)$ & $1.0[0.9-1.1]$ & $0.6[0.5-0.9]$ \\
$\mathrm{RMS}$ error $(\%)$ & $2.2[1.7-2.6]$ & $2.3[1.6-3.5]$ \\
PIP error $\left(\mathrm{cmH}_{2} \mathrm{O}\right)$ & $0.8[0.5-1.0]$ & $1.0[0.8-1.2]$ \\
PIP error $(\%)$ & $0.0[0.0-0.0]$ & $0.0[0.0-0.0]$ \\
\hline
\end{tabular}

show that prediction errors are similar for all initial PEEP levels, whether the PEEP step increases are 2 $\mathrm{cmH}_{2} \mathrm{O}$ or $6 \mathrm{cmH}_{2} \mathrm{O}$. There is thus no noticeable sensitivity to PEEP level or PEEP interval in prediction error.

Examples of best and worst case parabolic model predictions are shown in Fig. 6. Prediction error was fairly consistent across the entire CURE cohort, as can be seen in Figs. 7 and 8. The McREM cohort examples show that the model struggles to capture the non-linear behaviour in the end-inspiratory pause. However, the model was not designed to specifically capture this behaviour, which has a relatively low clinical risk in volume controlled ventilation as the plateau pressure is lower than the PIP. ${ }^{4}$ This error can result in over- or under-prediction of PIP and significant negative spikes near the beginning of expiration. Nevertheless, the RMS and PIP prediction errors in Table 4 remain generally better for the McREM cohort than for the CURE cohort.

\section{Comparison Between Exponential and Parabolic Prediction Model}

Figure 7 shows that PIP prediction error is lowest across the entire PEEP range studied in both cohorts when using the parabolic model. The difference in error also includes much lower outliers so the 95th percentile errors in Fig. 7 are $30-40 \%$ lower (relative) for both cohorts. Prediction fit error (RMS) was also lower in both cohorts. More specific results can be seen in the boxplots in Fig. 8, which presents these results by $\triangle$ PEEP prediction interval, again showing little sensitivity to this value for the new model.

\section{Inclusion of Expiratory Data}

The impact of using different sections of the breath data to fit elastance and resistance was explored for both the parabolic (Eq. 2) and exponential (Eq. 3) models. Results are shown in Table 5, and cover cases 1 and 2 as defined in "Impact of the Inclusion of Expiratory Data in Model Fit and Prediction".

The parabolic model has lower RMS errors for all cases tested except for inspiration data from the CURE trial. These results clearly indicate that the parabolic model generally captures and predicts observed lung dynamics better than the exponential model.

The parabolic model also predicted PIP better in all cases, except for inspiration in the CURE trial. However, the exponential model produced very erroneous predictions for the McREM data set. A third case of only fitting the model to inspiration data while predicting across the entire breath had comparable results 
Patient 2, McREM Data Set
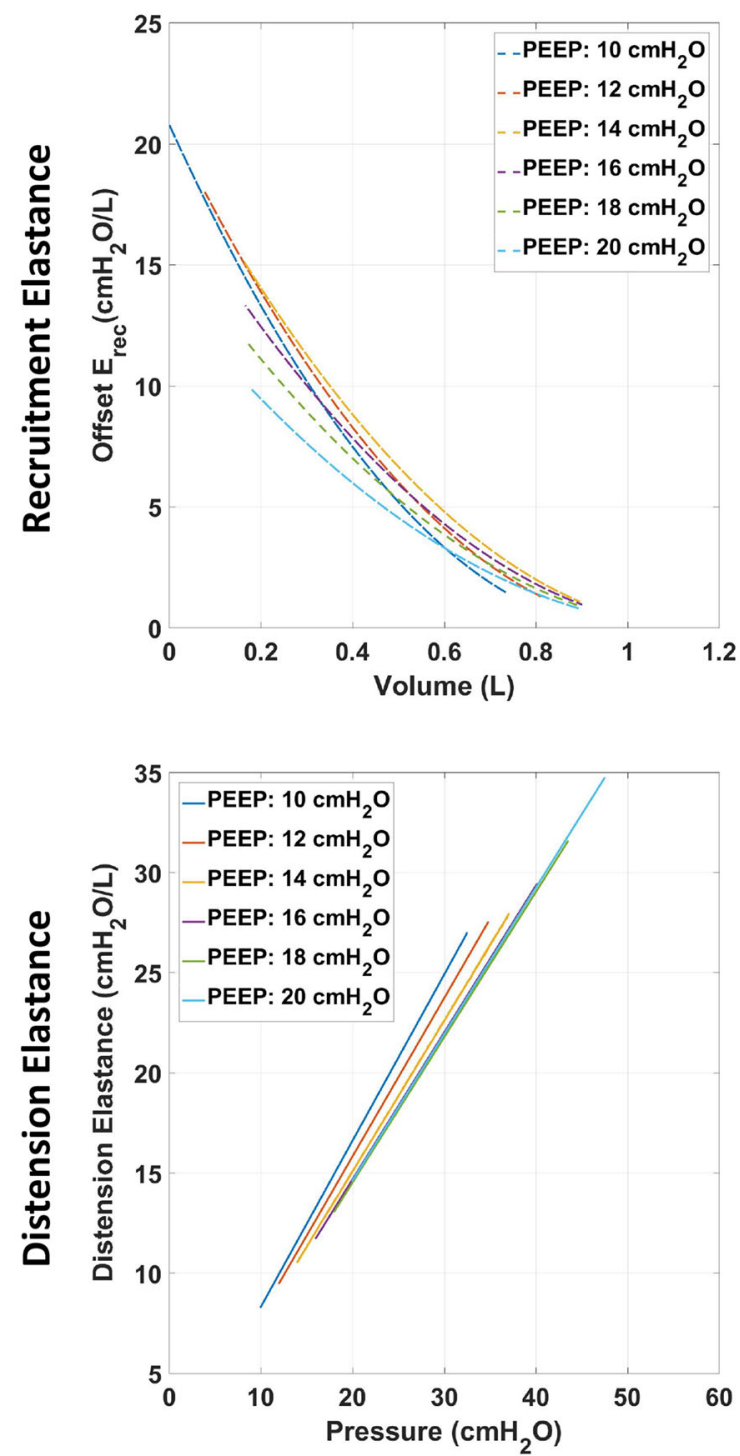

Patient 5, McREM Data Set
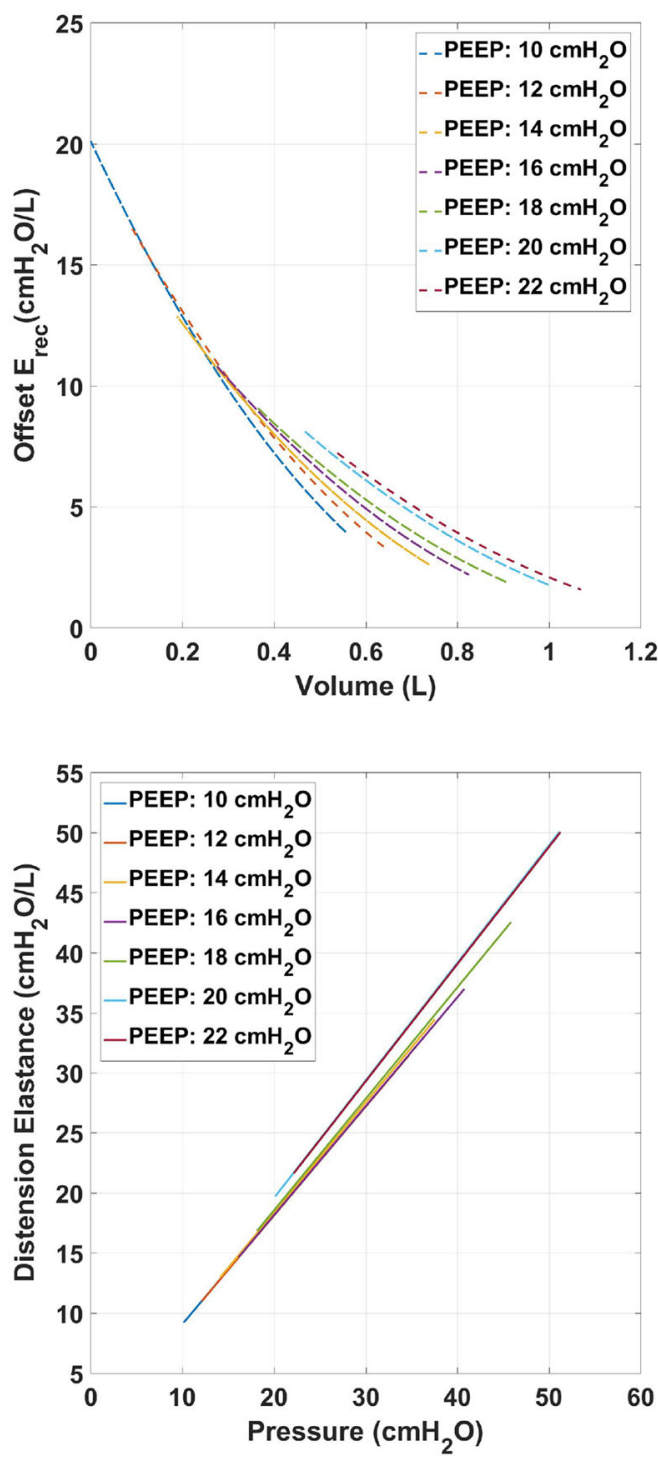

FIGURE 4. Recruitment and distension elastance curves across PEEP steps, including the associated volume gain offsets relative to the lowest PEEP data.

TABLE 4. Aggregated prediction errors for each PEEP change across both cohorts of patients studied $\left(1 \mathrm{cmH}_{2} \mathrm{O}=98.07 \mathrm{~Pa}\right)$.

\begin{tabular}{lccc}
\hline & \# of predictions studied & RMS error $\left(\mathrm{cmH}_{2} \mathrm{O}\right)$ & PIP error $\left(\mathrm{cmH}_{2} \mathrm{O}\right)$ \\
\hline $2 \mathrm{cmH}_{2} \mathrm{O}$ PEEP increase & 77 & $1.2[0.9-1.4]$ & $1.3[-0.6$ to 2.2] \\
$4 \mathrm{cmH}_{2} \mathrm{O}$ PEEP increase & 75 & $1.1[1.0-1.1]$ & $1.3[0.8-1.7]$ \\
$6 \mathrm{cmH}_{2} \mathrm{O}$ PEEP increase & 47 & $1.7[1.2-2.0]$ & $0.7[-1.7$ to 2.2] \\
$8 \mathrm{cmH}_{2} \mathrm{O}$ PEEP increase & 41 & $1.1[1.0-1.3]$ & $1.3[1.2-2.2]$ \\
$10 \mathrm{cmH}_{2} \mathrm{O}$ PEEP increase & 23 & $1.7[1.1-1.9]$ & $1.2[0.2-3.6]$ \\
$12 \mathrm{cmH}_{2} \mathrm{O}$ PEEP increase & 16 & $1.3[1.2-1.5]$ & $2.2[1.2-3.1]$ \\
$14 \mathrm{cmH}_{2} \mathrm{O}$ PEEP increase & 8 & $1.8[1.4-1.9]$ & $1.8[0.6-3.8]$ \\
$16 \mathrm{cmH}_{2} \mathrm{O}$ PEEP increase & 6 & $1.6[1.4-1.7]$ & $3.3[1.3-3.9]$ \\
\hline
\end{tabular}



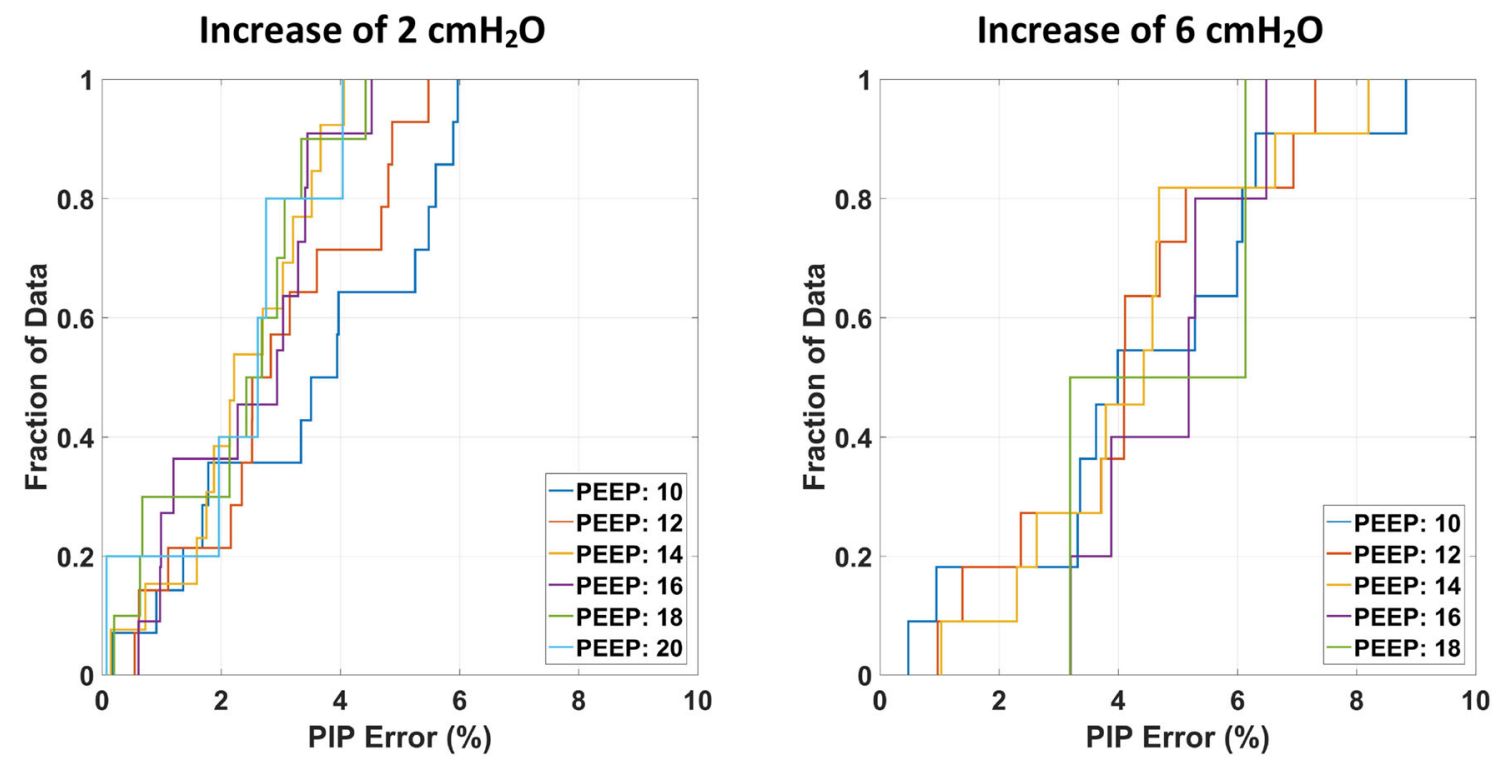

FIGURE 5. Cumulative distribution functions (CDFs) showing consistent prediction errors across all PEEP levels for step increases of 2 and $6 \mathrm{cmH}_{2}$. The PEEP shown in the legend is the initial PEEP level from which a prediction is made.

to including inspiration data only in PIP prediction, as shown in the CDFs in Fig. 9. The inclusion of expiratory data did not improve prediction for smaller PEEP changes for the McREM data. However, comparable results between the three cases studied were seen for larger changes of PEEP. Using all available data improved the prediction fit error in both cohorts, as seen in Fig. 9, and is clearly the best case.

\section{DISCUSSION}

Prediction of patient-specific lung mechanics throughout recruitment manoeuvres has previously been examined using an exponential basis function model for recruitment elastance. ${ }^{35}$ The choice of an exponential model was consistent with a large number of prior clinical observations. ${ }^{15,34,37,46,58}$ The current study uses a much larger data set than in Ref. 35 to test this assumption vs. a new parabolic recruitment model. It also examines all major assumptions in the methods and model parameter choices to assess robustness.

The choice of basis functions in Figs. 2 and 3 and as defined in Eqs. (2) and (3) is based on fundamental mechanical principles applied to the lung mechanics situation. Thus, elastance is based on the competing mechanics of recruitment opening new volume $\left(E_{1}\right)$ and distension at higher pressures $\left(E_{2}\right)$. These two terms are based on direct clinical observations of elastance and distension across a breath, ${ }^{13}$ where the hyperbolic shape chosen was a good match for the results of. ${ }^{13}$ Equally, the resistance basis functions are based on the well-known Rohrer Equation ${ }^{40}$ capturing the linear and quadratic elements of flow resistance.

It is always possible that the generic hyperbolic and linear elastance basis functions and/or the Rohrer Equation based resistance basis functions are not the exact or optimal form. Prior work ${ }^{35}$ has used exponential recruitment basis functions and other similar shapes may better suit some patients or disease states. However, given the breath to breath variability in typical patients and any noise on the data, differentiating between several similar shaped functions would be difficult. Equally, prior works examining more complex basis functions found no improvement and greater identifiability problems, where identifiability limits the complexity of possible basis function shapes given the limited data. ${ }^{11,19}$

Table 4 and Fig. 4 show that prediction error is reasonably consistent across variable PEEP levels used to generate prediction and consistent prediction ranges. However, the prediction error changes noticeably when there are consistent PEEP levels used for prediction and variable prediction ranges. The errors are still clinically acceptable and relatively small compared to inter- and intra- patient variability, but do grow as the model is "stretched" to predict over larger intervals. The success at prediction in the results thus validates the choice of basis function shapes, as well as their potential to accurately capture mechanics outside the range of breath data used to identify their parameters.

Previous work ${ }^{35}$ was only validated over eight RMs from four patients who were treated in the same care 


\section{CURE Cohort}

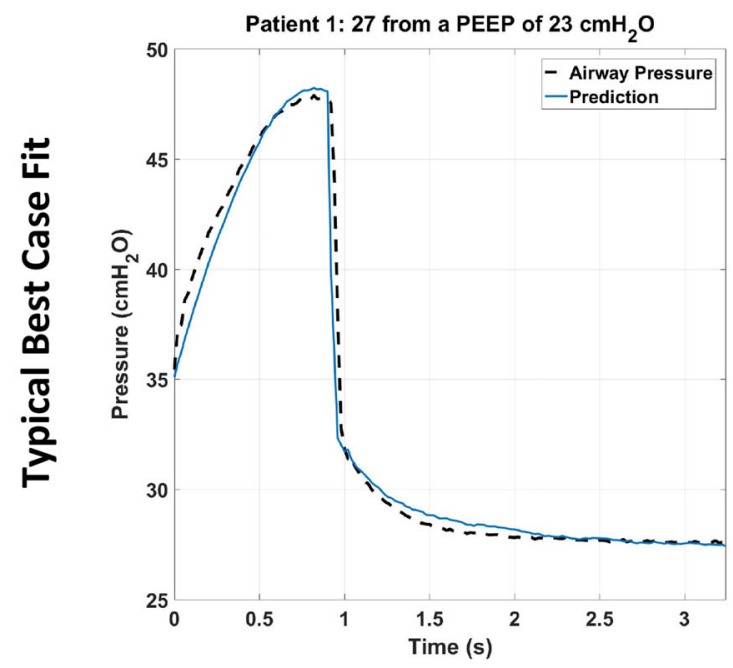

Parameters:

$E_{1}=19.7, E_{2}=54.5, R_{1}=7.0, R_{2}=0.0$

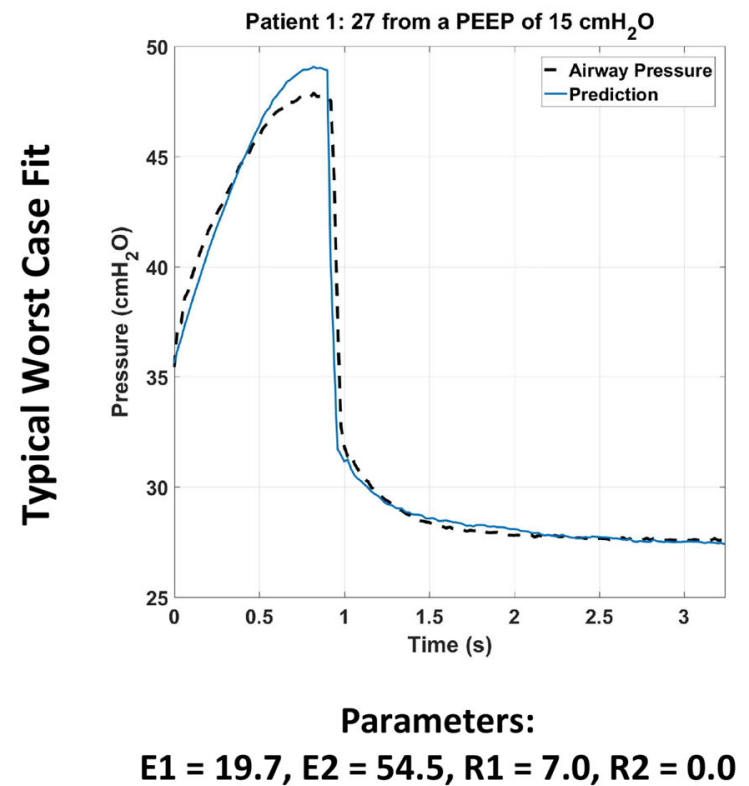

McREM Cohort

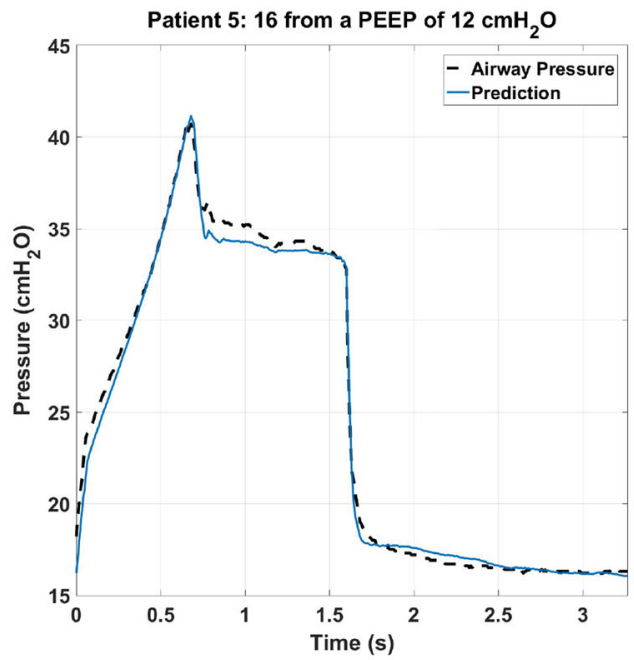

Parameters:

$$
E_{1}=20.1, E_{2}=54.4, R_{1}=6.6, R_{2}=0.0
$$

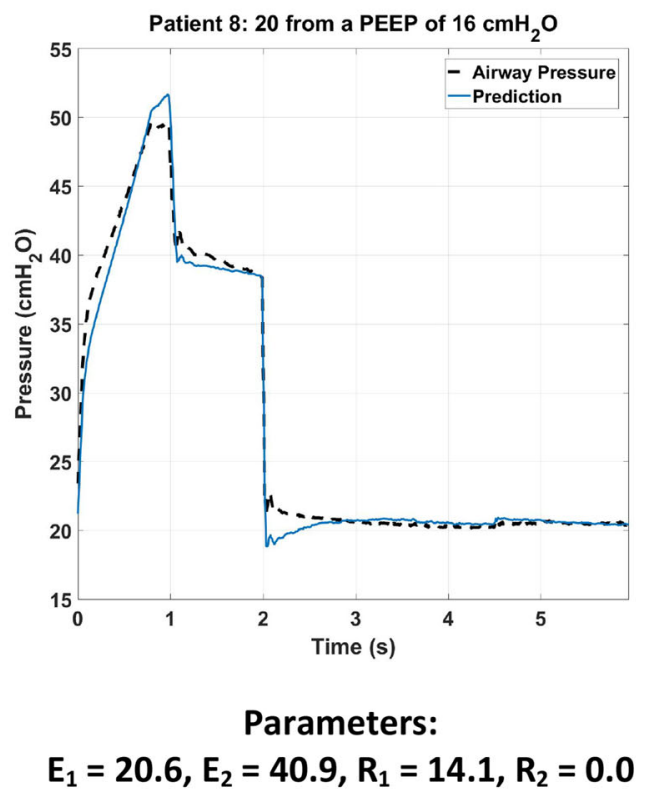

FIGURE 6. Typical examples of model predictions for CURE and McREM cohorts.

unit. In addition, while the patients exhibited a range of lung mechanics and varying degrees of ARDS, three of these patients were diagnosed with pneumonia which may have limited the diversity of results. In the current study, the McREM data includes patients from eight different ICUs, ${ }^{43}$ on a different continent and clinical practice culture from the original CURE study. The use of this additional data set and an improved model in this study further validates the overall model and prediction approach as generalizable to other ICU contexts. It also indicates that the model can accurately predict underlying lung mechanics across a wider range of lung conditions.

The use of a data set using PEEP steps of $2 \mathrm{cmH}_{2} \mathrm{O}$ as opposed to $4 \mathrm{cmH}_{2} \mathrm{O}$ in Ref. 35, further demonstrates the versatility of the model. As the prediction aspect of the model is based on estimation of additional lung volume $\left(V_{\text {frc }}\right)$ at each step, the accumulation of error is expected to be greater when there is a higher number of PEEP changes across a small PEEP prediction interval. However, prediction error for changes of up to $12 \mathrm{cmH}_{2} \mathrm{O}\left(6 \times 2 \mathrm{cmH}_{2} \mathrm{O}\right.$ in 

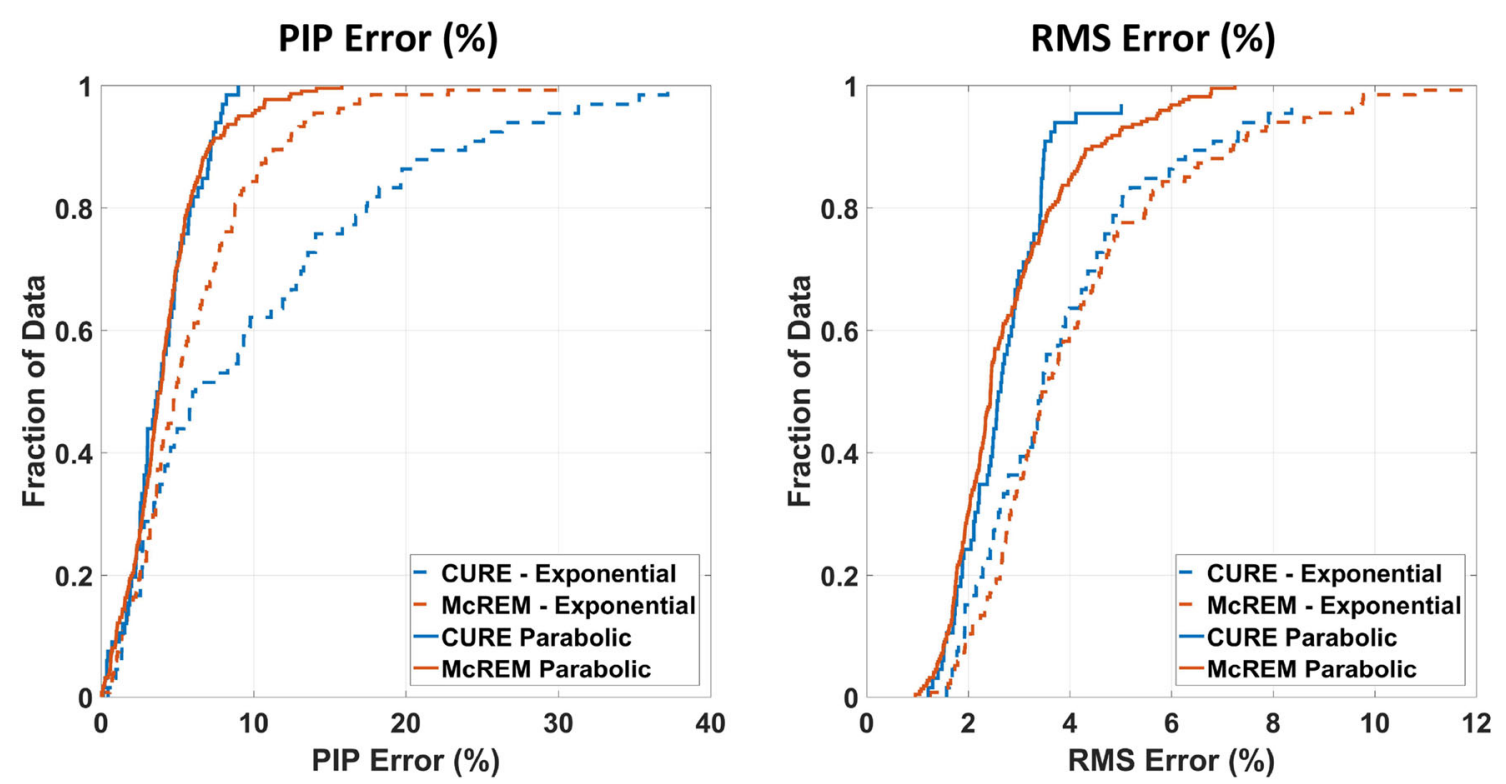

FIGURE 7. CDF comparison of PIP prediction and prediction results between exponential and parabolic model for elastance as a function of recruitment. Errors are shown for both the CURE and McREM cohorts.

McREM; $3 \times 4 \mathrm{cmH}_{2} \mathrm{O}$ in CURE) remained below $15 \%$ for the McREM cohort and 10\% for the CURE cohort. Errors within this range were thus within bounds of reasonable clinical safety.

Overall, fit and prediction error were low for the parabolic form of the model for all data sets studied. All error metrics were comparable for fit for both the CURE and the McREM data. Prediction error (median [IQR]) for all patients increased as expected with increasing PEEP changes over the range studied (2$\left.16 \mathrm{cmH}_{2} \mathrm{O}\right)$. PIP prediction error was 1.0 [0.6-1.7] $\mathrm{cmH}_{2} \mathrm{O}$ (median [IQR]) and 2.9 [2.0-4.5] \% PIP error for PEEP changes up to $16 \mathrm{cmH}_{2} \mathrm{O}$; a prediction error that is likely clinically insignificant.

In addition, prediction accuracy appears to be independent of the starting PEEP level, suggesting the model captures lung dynamics across the entire pressure range well, and thus it can be used with similar levels of accuracy throughout an entire recruitment manoeuvre. However, more data from more patients and a wider number of ICU contexts should be used to confirm these findings.

Recruitment has been widely assumed to follow an exponential decay with increasing pressure. ${ }^{15,34,37,46,58}$ However, when used in concert with distension for the purposes of lung mechanics prediction, it may not provide the most accurate depiction of dynamics. The parabolic recruitment basis function model considerably improved prediction accuracy in both cohorts compared to the previous exponential model of Ref. 35 . There was a considerable increase in accuracy with the parabolic definition seen in the CURE cohort, with no predictions having more than $10 \%$ error in PIP prediction for PEEP increases of up to $14 \mathrm{cmH}_{2} \mathrm{O}$. While still demonstrating improvements, the McREM data exhibited lower prediction error than the CURE cohort.

Traditionally, recruitment is typically related to pressure, where threshold pressures govern alveolar opening and closing. However, in this case the elastance basis function used here is a function of volume. This exponential or parabolic elastance basis function describes the apparent decrease in elastance, given a constant tissue stiffness, as volume increases. ${ }^{29}$ This function implicitly assumes the pressure-dependant opening of alveoli, without being an explicit function of pressure.

Using the full breath data set improved prediction in the CURE cohort. However, it introduced some interesting features into the pressure predictions for the McREM cohort. In particular, it did not capture the inspiratory pause (shown in Figs. 6b-6d) in the McREM data well, and introduced a deeper pressure drop at the start of expiration. It is likely that this difference is due to the model attempting to account for relaxation and redistribution of gas in the parenchyma during the end-inspiratory pause without specific consideration of this affect during model design. However, prediction fit error (RMS) improved with the use of the additional expiration data in both cohorts, indicating the model fit the overall dynamics better, despite these anomalies.

In addition, the length of expiration and inspiration are equal in the McREM data: a 1:1 inspiratory to 


\section{Exponential Model}
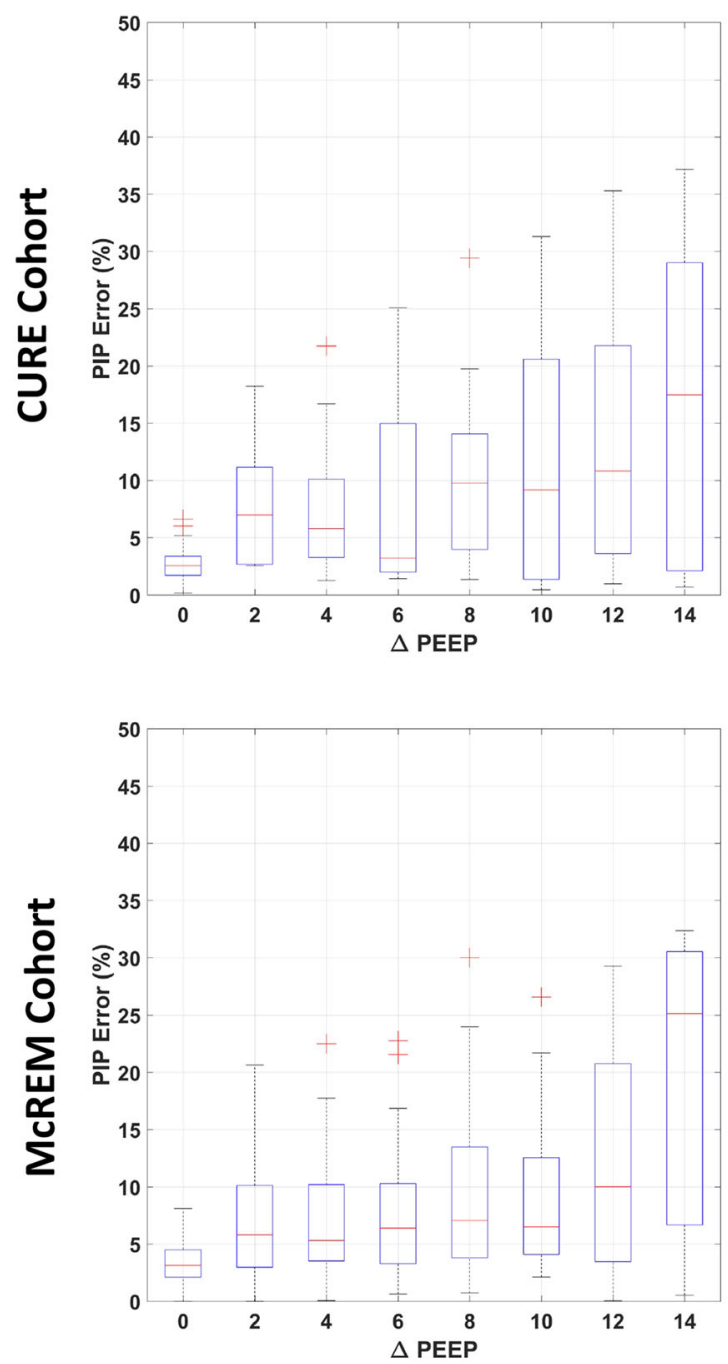

Parabolic Model
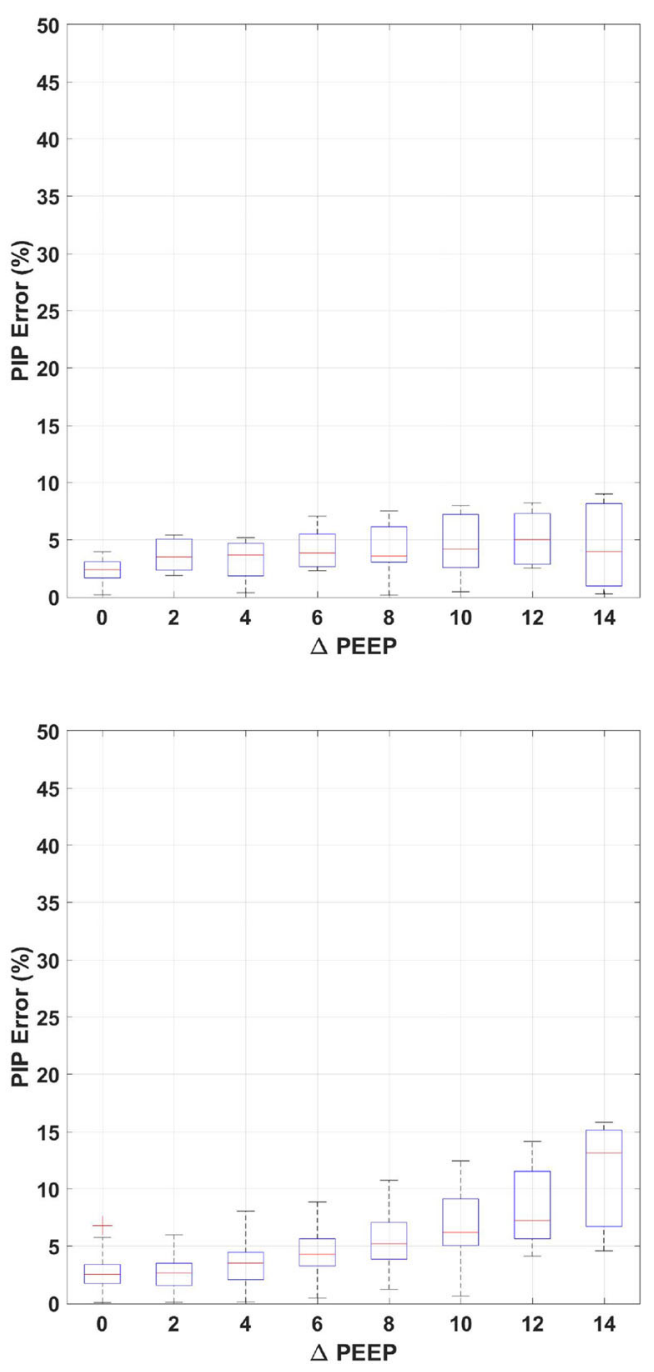

FIGURE 8. Boxplot comparisons of PIP prediction results between exponential and parabolic model for elastance as a function of recruitment. Errors are shown for both the CURE and McREM cohorts, and box plots reflect the CDFs in Fig. 5 .

TABLE 5. Impact of the inclusion of expiratory data in prediction accuracy for PEEP increases of up to $16 \mathrm{cmH}_{2} \mathrm{O}$, indicated by PIP \% error (median [IQR]) $\left(1 \mathrm{cmH}_{2} \mathrm{O}=98.07 \mathrm{~Pa}\right)$.

\begin{tabular}{|c|c|c|c|c|}
\hline & \multicolumn{2}{|c|}{ CURE data } & \multicolumn{2}{|c|}{ McREM data } \\
\hline & RMS error $\left(\mathrm{cmH}_{2} \mathrm{O}\right)$ & PIP error (\%) & RMS error $\left(\mathrm{cmH}_{2} \mathrm{O}\right)$ & PIP error $(\%)$ \\
\hline Entire breath (exponential model) & $2.1[1.7-2.9]$ & $6.1[2.7-14.1]$ & $1.7[1.1-2.3]$ & $4.9[3.1-7.9]$ \\
\hline Inspiration only (exponential model) & $2.3[1.6-3.2]$ & $3.7[1.8-7.3]$ & $1.9[1.4-2.6]$ & $9.3[5.6-13.4]$ \\
\hline Fitted to inspiration, RMS assessed across entire breath & $2.5[1.9-3.1]$ & $N / A$ & $2.1[1.7-3.0]$ & $N / A$ \\
\hline Entire breath (parabolic model) & $1.2[1.0-1.5]$ & $3.8[2.5-5.4]$ & $0.9[0.6-1.1]$ & $3.9[2.4-5.3]$ \\
\hline Inspiration only (parabolic model) & $2.2[1.3-3.5]$ & $5.5[3.8-8.7]$ & $1.0[0.7-1.5]$ & $1.5[0.5-3.6]$ \\
\hline Fitted to inspiration, RMS assessed across entire breath & $2.6[2.0-3.0]$ & $\mathrm{N} / \mathrm{A}$ & $1.0[0.8-1.4]$ & $\mathrm{N} / \mathrm{A}$ \\
\hline
\end{tabular}

expiratory (I:E) ratio. However, expiration is twice as long as inspiration in the CURE cohort due to different ventilator settings on the $I: E$ ratio at 1:2. It was found (not shown here) that weighting or using equal amounts of inspiration and expiration data for the CURE data cohort had model-prediction errors simi- 


\section{CURE Data}
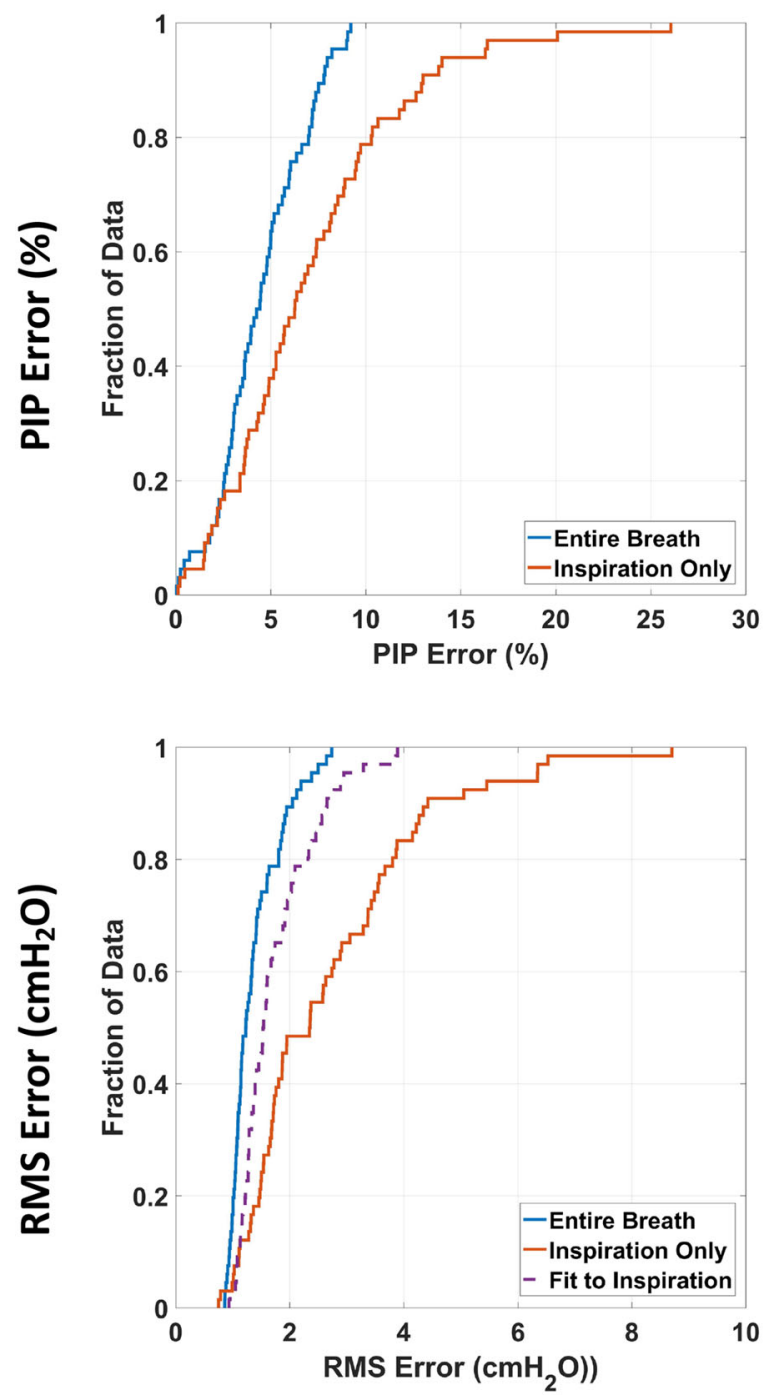

McREM Data
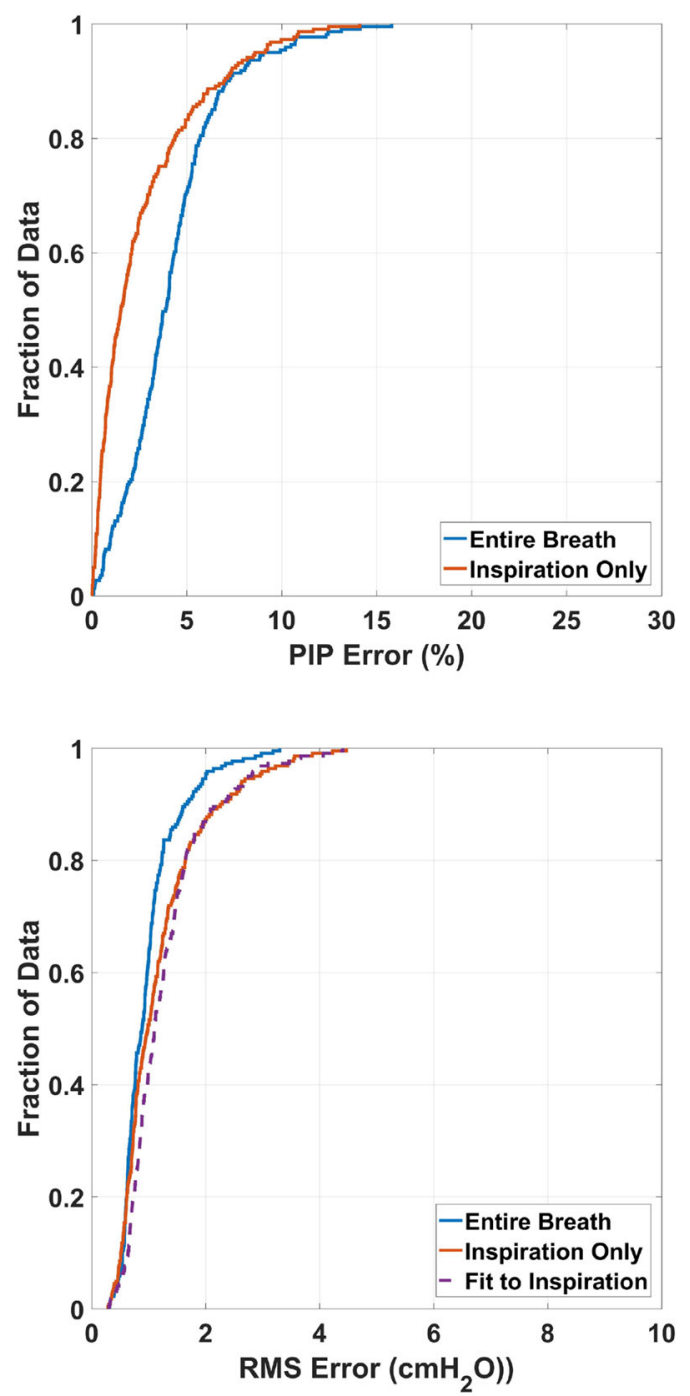

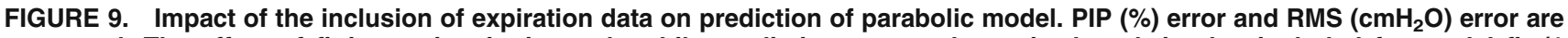
presented. The effect of fitting to inspiration only while predicting across the entire breath is also included for model fit (1 $\mathrm{cmH}_{2} \mathrm{O}=98.07 \mathrm{~Pa}$ ).

lar to fitting across the entire breath however did not offer an improvement. Thus, the CURE data results presented here are not unfairly biased towards expiration.

\section{Limitations}

Due to the low number of patients in the CURE cohort, conclusions cannot be drawn as to whether or not fitting basis functions to an entire breath with unequal lengths of inspiration and expiration is necessarily beneficial. In addition to this, the model would need to be re-fit if major changes were made to ventilation such as a new tidal volume. Future work should consider other volume controlled data sets that do not include an end-inspiratory pause, and differing inspiration and expiration durations to assess any impact. However, the results are encouraging.

The proposed basis functions used in this study mimic the basic shapes of major modes of changes in elastance. The fact that they result in excellent predictions for their relative degree of simplicity leads us to believe that they broadly capture key dynamics. Further validation of the basis functions is not possible given the current data set given the lack of imaging or other independent data against which to make a validation comparison.

This paper is thus limited to proof of concept over a modestly diverse, and larger cohort of patients. The association of parameter values and evolution with 
disease state and/or clinical outcomes is best served by a larger study and a separate paper from which decisive conclusions might arise.

Previous work ${ }^{36}$ has shown promising results for the exponential model being able to predict lower PEEP levels throughout the downwards section of a recruitment manoeuvre arm. While this study did not aim to validate this capability for the parabolic form of the model, there is less of a clinical need for this as reducing pressure is lowering risk.

While the field is increasingly moving towards the use of pressure controlled ventilation, at this stage the model has only been tested on volume controlled ventilation. However, the model and methods are generalisable enough to predict lung mechanics depending on the controlled variable (pressure or volume). While such data was not available to the authors in this study, testing the model on pressure controlled ventilation data would further validate the model, method and outcomes presented.

\section{Summary}

This work compared the exponential recruitment model of Ref. 35 against a parabolic model to determine which method provides the better prediction of lung mechanics throughout recruitment manoeuvres. The parabolic model significantly improved model fit and prediction in this cohort, suggesting this shape better captures the recruitment process of alveoli as PEEP and pressure change, in contrast to common modelling assumptions. A larger data set enabled robustness analysis of individual modelling decisions, finding use of the entire set of breath data improved accuracy, and the choice of fixed model parameters was robust. The overall model provides a significant improvement in predictive, and thus clinical, utility.

\section{ACKNOWLEDGMENTS}

This work was supported by the NZ Tertiary Education Commission (TEC) fund MedTech CoRE (E6391) (Centre of Research Expertise) and the NZ National Science Challenge 7, Science for Technology and Innovation (E6525). The authors also acknowledge support from the Engineering Technology-based Innovation in Medicine (eTIME) consortium grant [eTIME 318943]; the EU FP7 International Research Staff Exchange Scheme (IRSES) Grant [\#PIRSESGA-2012-318943].

\section{REFERENCES}

${ }^{1}$ Albert, S. P., J. D. Dirocco, G. B. Allen, J. H. T. Bates, R. Lafollette, B. D. Kubiak, J. Fischer, S. Maroney, and G. F. Nieman. The role of time and pressure on alveolar recruitment. J. Appl. Physiol. 106:757-765, 2009.

${ }^{2}$ Amato, M. B. P., C. S. V. Barbas, D. M. Medeiros, R. B. Magaldi, G. P. Schettino, G. Lorenzi-Filho, R. A. Kairalla, D. Deheinzelin, C. Munoz, R. Oliveira, and T. Y. Takagaki. Effect of a protective-ventilation strategy on mortality in the acute respiratory distress syndrome. $N$. Engl. J. Med. 338:347-354, 1998.

${ }^{3}$ Amato, M. B. P., M. O. Meade, A. S. Slutsky, L. Brochard, E. L. V. V. Costa, D. A. Schoenfeld, T. E. Stewart, M. Briel, D. Talmor, A. Mercat, J. C. M. Richard, C. R. R. Carvalho, and R. G. Brower. Driving pressure and survival in the acute respiratory distress syndrome. N. Engl. J. Med. 372:747-755, 2015.

${ }^{4}$ Bates, J. H. T. Lung Mechanics: An Inverse Modeling Approach. Cambridge: Cambridge University Press, 2009. ${ }^{5}$ Bates, J. H. T., and C. G. Irvin. Time dependence of recruitment and derecruitment in the lung: a theoretical model. J. Appl. Physiol. 93:705-713, 2002.

${ }^{6}$ Borges, B., V. N. Okamoto, G. F. J. Matos, M. P. R. Caramez, P. R. Arantes, F. Barros, C. E. Souza, A. Victorino, R. M. Kacmarek, C. S. V. Barbas, C. R. R. Carvalho, and M. B. P. Amato. Reversibility of lung collapse and hypoxemia in early acute respiratory distress syndrome. Am. J. Respir. Crit. Care Med. 174:268-278, 2006. ${ }^{7}$ Briel, M., M. O. Meade, A. Mercat, R. G. Brower, D. Talmor, S. D. Walter, A. S. Slutsky, L. Brochard, T. E. Stewart, E. Pullenayegum, Q. Zhou, D. J. Cook, J.-C. M. Richard, F. Lamontagne, N. Bhatnagar, and G. H. Guyatt. Higher vs lower positive end-expiratory pressure in patients with acute lung injury. JAMA J. Am. Med. Assoc. 303:865-873, 2010.

${ }^{8}$ Brower, R. G., P. N. Lanken, N. Macintyre, M. A. Matthay, A. Morris, M. Ancukiewicz, D. A. Schoenfeld, B. T. Thompson, and T. N. H. L. and B. I. A. C. T. Network*. Higher versus lower positive end-expiratory pressures in patients with the acute respiratory distress syndrome. $N$. Engl. J. Med. 351:113-116, 2004.

${ }^{9}$ Brower, R. G., M. A. Matthay, A. Morris, D. A. Schoenfeld, B. T. Thompson, A. Wheeler, and The Acute Respiratory Distress Syndrome Network. Ventilation with lower tidal volumes as compared with traditional tidal volumes for acute lung injury and the acute respiratory distress syndrome. N. Engl. J. Med. 342:1301-1308, 2000.

${ }^{10}$ Caironi, P., M. Cressoni, D. Chiumello, M. Ranieri, M. Quintel, S. G. Russo, R. Cornejo, G. Bugedo, E. Carlesso, R. Russo, L. Caspani, and L. Gattinoni. Lung opening and closing during ventilation of acute respiratory distress syndrome. Am. J. Respir. Crit. Care Med. 181:578-586, 2010.

${ }^{11}$ Chase, J. G., J.-C. Preiser, J. L. Dickson, A. Pironet, Y.-S. Chiew, C. G. Pretty, G. M. Shaw, B. Benyó, K. Moeller, S. Safaei, M. H. Tawhai, P. Hunter, and T. Desaive. Nextgeneration, personalised, model-based critical care medicine: a state-of-the art review of in silico virtual patient models, methods, and cohorts, and how to validation them. Biomed. Eng. Online 17:24, 2018. 
${ }^{12}$ Chiew, Y.-S., J. G. Chase, G. M. Shaw, A. Sundaresan, and T. Desaive. Model-based PEEP optimisation in mechanical ventilation. Biomed. Eng. Online 10:111, 2011.

${ }^{13}$ Chiew, Y.-S., C. G. Pretty, P. D. Docherty, B. Lambermont, G. M. Shaw, T. Desaive, and J. G. Chase. Timevarying respiratory system elastance: a physiological model for patients who are spontaneously breathing. PLoS ONE 10:e0114847, 2015.

${ }^{14}$ Crampin, E. J., M. Halstead, P. Hunter, P. Nielsen, D. Noble, N. Smith, and M. Tawhai. Computational physiology and the physiome project. Exp. Physiol. 89:1-26, 2004.

${ }^{15}$ Crotti, S., D. Mascheroni, P. Caironi, P. Pelosi, G. Ronzoni, M. Mondino, J. J. Marini, and L. Gattinoni. Recruitment and derecruitment during acute respiratory failure. Am. J. Respir. Crit. Care Med. 164:131-140, 2001.

${ }^{16}$ Davidson, S. M., D. P. Redmond, H. Laing, R. White, F. Radzi, Y.-S. Chiew, S. F. Poole, N. S. Damanhuri, T. Desaive, G. M. Shaw, and J. G. Chase. Clinical utilisation of respiratory elastance (CURE): pilot trials for the optimisation of mechanical ventilation settings for the critically Ill. IF AC Proc. 19:8403-8408, 2014.

${ }^{17}$ de Matos, G. F. J., F. Stanzani, R. H. Passos, M. F. Fontana, R. Albaladejo, R. E. Caserta, D. C. B. Santos, J. B. Borges, M. B. P. Amato, and C. S. V. Barbas. How large is the lung recruitability in early acute respiratory distress syndrome: a prospective case series of patients monitored by computed tomography. Crit. Care 16:1-14, 2012.

${ }^{18}$ Dellamonica, J., N. Lerolle, C. Sargentini, G. Beduneau, F. Di Marco, A. Mercat, J.-C. M. Richard, J.-L. Diehl, J. Mancebo, J. J. Rouby, Q. Lu, G. Bernardin, and L. Brochard. PEEP-induced changes in lung volume in acute respiratory distress syndrome. Two methods to estimate alveolar recruitment. Intensive Care Med. 37:1595-1604, 2011.

${ }^{19}$ Docherty, P. D., J. G. Chase, T. F. Lotz, and T. Desaive. A graphical method for practical and informative identifiability analyses of physiological models: a case study of insulin kinetics and sensitivity. Biomed. Eng. Online 10:1-21, 2011.

${ }^{20}$ Dreyfuss, D., and G. Saumon. Barotrauma is volutrauma, but which volume is the one responsible? Intensive Care Med. 18:139-141, 1992.

${ }^{21}$ Flevari, A. G. G., N. Maniatis, T. E. Kremiotis, I. Siempos, A. P. P. Betrosian, C. Roussos, E. Douzinas, and A. Armaganidis. Rohrer's constant, K2, as a factor of determining inspiratory resistance of common adult endotracheal tubes. Anaesth. Intensive Care 39:410-417, 2011.

${ }^{22}$ Gammon, R. B., M. S. Shin, and S. E. Buchalter. Pulmonary barotrauma in mechanical ventilation: patterns and risk factors. Chest 102:568-572, 1992.

${ }^{23}$ Garcia, C. S. N. B., L. F. M. Prota, M. M. Morales, P. V. Romero, W. A. Zin, and P. R. M. Rocco. Understanding the mechanisms of lung mechanical stress. Brazilian J. Med. Biol. Res. 39:697-706, 2006.

${ }^{24}$ Graham, M. R., C. J. Haberman, J. F. Brewster, L. G. Girling, B. M. McManus, and W. A. C. Mutch. Mathematical modelling to centre low tidal volumes following acute lung injury: a study with biologically variable ventilation. Respir. Res. 6:1-11, 2005.

${ }^{25}$ Harris, R. S., D. R. Hess, and J. G. Venegas. An objective analysis of the pressure-volume curve in the acute respiratory distress syndrome. Am. J. Respir. Crit. Care Med. $161: 432-439,2000$.
${ }^{26}$ Hickling, K. G. The pressure-volume curve is greatly modified by recruitment a mathematical model of ARDS lungs. Am. J. Respir. Crit. Care Med. 158:194-202, 1998.

${ }^{27}$ Hodgson, C. L., D. V. Tuxen, A. R. Davies, M. J. Bailey, A. M. Higgins, A. E. Holland, J. L. Keating, D. V. Pilcher, A. J. Westbrook, D. J. Cooper, and A. D. Nichol. A randomised controlled trial of an open lung strategy with staircase recruitment, titrated PEEP and targeted low airway pressures in patients with acute respiratory distress syndrome. Crit. Care 15:133, 2011.

${ }^{28}$ Jarreau, P. H., B. Louis, G. Dassieu, L. Desfrere, P. W. Blanchard, G. Moriette, D. Isabey, and A. Harf. Estimation of inspiratory pressure drop in neonatal and pediatric endotracheal tubes. J. Appl. Physiol. 87:36-46, 1999.

${ }^{29}$ Kanangara, O., J. L. Dickson, and J. G. Chase. Specific compliance: is it truly independent of lung volume? IFACPapers Online 51:1-6, 2018.

${ }^{30}$ Lambermont, B., A. Ghuysen, N. Janssen, P. Morimont, G. Hartstein, P. Gerard, and V. D'Orio. Comparison of functional residual capacity and static compliance of the respiratory system during a positive end-expiratory pressure (PEEP) ramp procedure in an experimental model of acute respiratory distress syndrome. Crit. Care 12:R91, 2008.

${ }^{31}$ Langdon, R., P. D. Docherty, Y.-S. Chiew, K. Möller, and J. G. Chase. Use of basis functions within a non-linear autoregressive model of pulmonary mechanics. Biomed. Signal Process. Control 27:44-50, 2016.

${ }^{32} \mathrm{Ma}$, B., and J. H. T. Bates. Modeling the complex dynamics of derecruitment in the lung. Ann. Biomed. Eng. 38:3466-3477, 2010.

${ }^{33}$ Massa, C. B., G. B. Allen, and J. H. T. Bates. Modeling the dynamics of recruitment and derecruitment in mice with acute lung injury. J. Appl. Physiol. 105:1813-1821, 2008.

${ }^{34}$ Medoff, B. D., R. S. Harris, H. Kesselman, J. G. Venegas, M. B. P. Amato, and D. Hess. Use of recruitment maneuvers and high-positive end-expiratory pressure in a patient with acute respiratory distress syndrome. Crit. Care Med. 28:1210-1216, 2000.

${ }^{35}$ Morton, S. E., J. L. Dickson, J. G. Chase, P. D. Docherty, T. Desaive, S. L. Howe, G. M. Shaw, and M. H. Tawhai. A virtual patient model for mechanical ventilation. Comput. Methods Programs Biomed. 165:77-87, 2018.

${ }^{36}$ Morton, S. E., J. L. Dickson, J. G. Chase, P. D. Docherty, S. L. Howe, G. M. Shaw, and M. H. Tawhai. Development of a predictive pulmonary elastance model to describe lung mechanics throughout recruitment manoeuvres. IFAC-PapersOnLine 51:215-220, 2018.

${ }^{37}$ Mutch, W. A. C. Convexity, Jensen's inequality, and benefits of noisy or biologically variable life support. Proc. SPIE 5841:1-8, 2005.

${ }^{38}$ Owens, R. L., D. R. Hess, A. Malhotra, J. G. Venegas, and R. S. Harris. Effect of the chest wall on pressure-volume curve analysis of acute respiratory distress syndrome lungs. Crit. Care Med. 36:2980-2985, 2008.

${ }^{39}$ Ranieri, V. M., N. T. Eissa, C. Corbeil, M. Chassé, J. Braidy, N. Matar, and J. Milic-Emili. Effects of positive end-expiratory pressure on alveolar recruitment and gas exchange in patients with the adult respiratory distress syndrome. Am. Rev. Respir. Dis. 144:544-551, 1991.

${ }^{40}$ Rohrer, F. Physiologie der Atembewegung. In: Handbuch der normalen und pathologischen Physiologie, Vol. 2. Berlin: Springer, pp. 70-127, 1925.

${ }^{41}$ Slutsky, A. S. ACCP consensus conference-mechanical ventilation. Chest 104:1833-1859, 1993. 
${ }^{42}$ Slutsky, A. S., and L. N. Tremblay. Multiple system organ failure: is mechanical ventilation a contributing factor? Am. J. Physiol. 157:1721-1725, 1998.

${ }^{43}$ Stahl, C. A., K. Moeller, S. Schumann, R. Kuhlen, M. Sydow, C. Putensen, and J. Guttmann. Dynamic versus static respiratory mechanics in acute lung injury and acute respiratory distress syndrome. Crit. Care Med. 34:20902098, 2006.

${ }^{44}$ Suarez-Sipmann, F., S. H. Böhm, G. Tusman, T. Pesch, O. Thamm, H. Reissmann, A. Reske, A. Magnusson, and G. Hedenstierna. Use of dynamic compliance for open lung positive end-expiratory pressure titration in an experimental study. Crit. Care Med. 35:214-221, 2007.

${ }^{45}$ Sundaresan, A., J. G. Chase, G. M. Shaw, Y.-S. Chiew, and T. Desaive. Model-based optimal PEEP in mechanically ventilated ARDS patients in the intensive care unit. Biomed. Eng. Online 10:64, 2011.

${ }^{46}$ Sundaresan, A., T. Yuta, C. E. Hann, J. G. Chase, G. M. Shaw, and J. G. Chase. A minimal model of lung mechanics and model-based markers for optimizing ventilator treatment in ARDS patients. Comput. Methods Programs Biomed. 95:166-180, 2009.

${ }^{47}$ Suter, P. M., H. B. Fairley, and M. D. Isenberg. Effect of tidal volume and positive end expiratory pressure on compliance during mechanical ventilation. Chest 73:158$162,1978$.

${ }^{48}$ Swan, A. J., A. R. Clark, and M. H. Tawhai. A computational model of the topographic distribution of ventilation in healthy human lungs. J. Theor. Biol. 300:222-231, 2012.

${ }^{49}$ Szlavecz, A., Y.-S. Chiew, D. P. Redmond, A. Beatson, D. Glassenbury, S. Corbett, V. Major, C. G. Pretty, G. M. Shaw, B. Benyó, T. Desaive, and J. G. Chase. The clinical utilisation of respiratory elastance software (CURE Soft): a bedside software for real-time respiratory mechanics monitoring and mechanical ventilation management. Biomed. Eng. Online 13:140, 2014.

${ }^{50}$ Tawhai, M. H., and J. H. T. Bates. Multi-scale lung modeling. J. Appl. Physiol. 110:1466-1472, 2011.

${ }^{51}$ Tawhai, M. H., and K. S. Burrowes. Developing integrative computational models of pulmonary structure. Anat. Rec. B. New Anat. 275:207-218, 2003.
${ }^{52}$ Tawhai, M. H., and K. S. Burrowes. Multi-scale models of the lung airways and vascular system. Integr. Respir. Control 605:190-194, 2008.

${ }^{53}$ Tawhai, M. H., A. J. Pullan, and P. J. Hunter. Generation of an anatomically based three-dimensional model of the conducting airways. Ann. Biomed. Eng. 28:793-802, 2000.

${ }^{54}$ The Mathworks. MATLAB R2017a., 2017.

${ }^{55}$ Valentini, R., J. Aquino-Esperanza, I. Bonelli, and P. Maskin. Gas exchange and lung mechanics in patients with acute respiratory distress syndrome: comparison of three different strategies of positive end expiratory pressure. $J$. Crit. Care 30:334-340, 2014.

${ }^{56}$ van Drunen, E. J., J. G. Chase, Y.-S. Chiew, G. M. Shaw, and T. Desaive. Analysis of different model-based approaches for estimating dFRC for real-time application. Biomed. Eng. Online 12:9, 2013.

${ }^{57}$ van Drunen, E. J., Y.-S. Chiew, C. G. Pretty, G. M. Shaw, B. Lambermont, N. Janssen, J. G. Chase, and T. Desaive. Visualisation of time-varying respiratory system elastance in experimental ARDS animal models. BMC Pulm. Med. 14:1-9, 2014.

${ }^{58}$ Venegas, J. G., R. S. Harris, and B. A. Simon. A comprehensive equation for the pulmonary pressure-volume curve. J. Appl. Physiol. 84:389-395, 1998.

${ }^{59}$ Wallet, F., B. Delannoy, A. Haquin, S. Debord, V. Leray, G. Bourdin, F. Bayle, J.-C. M. Richard, L. Boussel, and C. Guerin. Evaluation of recruited lung volume at inspiratory plateau pressure with PEEP using bedside digital chest Xray in patients with acute lung injury/ARDS. Respir. Care 58:416-423, 2013.

${ }^{60}$ Williamson, J. P., R. A. McLaughlin, W. J. Noffsinger, A. L. James, V. A. Baker, A. Curatolo, J. J. Armstrong, A. Regli, K. L. Shepherd, G. B. Marks, D. D. Sampson, D. R. Hillman, and P. R. Eastwood. Elastic properties of the central airways in obstructive lung diseases measured using anatomical optical coherence tomography. Am. J. Respir. Crit. Care Med. 183:612-619, 2011.

Publisher's Note Springer Nature remains neutral with regard to jurisdictional claims in published maps and institutional affiliations. 